\title{
The influence of the throttle inclination characteristics of a SI engine on fuel consumption in driving cycles
}

This dissertation shows the analysis of the selected indicators of the work of a passenger vehicle drivetrain designated with the use of the Road Load Engine Simulator. In a digital simulation, an internal - combustion engine is saved in a form of numerical speed characteristics in the computers memory. Basing on a virtual vehicle, some indicators of the drivetrain of a passenger vehicle have been determined, while driving with five electronic throttle inclination regulator settups. The simulation results of e.g., throttle repeal speeds and fuel consumtion are summarized in a tabular and graphic form and some of them are expressed per 100 kilometer of the distance covered. Both synthetic and real driving cycles were analyzed during the study and their influence on the egines fuel consumption was also shortly described.

Key words: fuel consumption, driving cycle, NEDC, throttle inclination regulator, simulation

\section{Introduction}

The increase in human mobility and the ways of using internal combustion engines contribute to the progress of environmental pollution. The high technical standard of modern vehicles is partly forced by the aspect of the cleanliness of our environment. Together with the mass automobile production it caused the access to vehicles with combustion engines to be easy for a great part of the population (Fig. 1). The increase in global fuel consumption, noticed in the last twenty years, results with an increase of toxic exhaust gases emissions, which have a destructive influence on our environment.

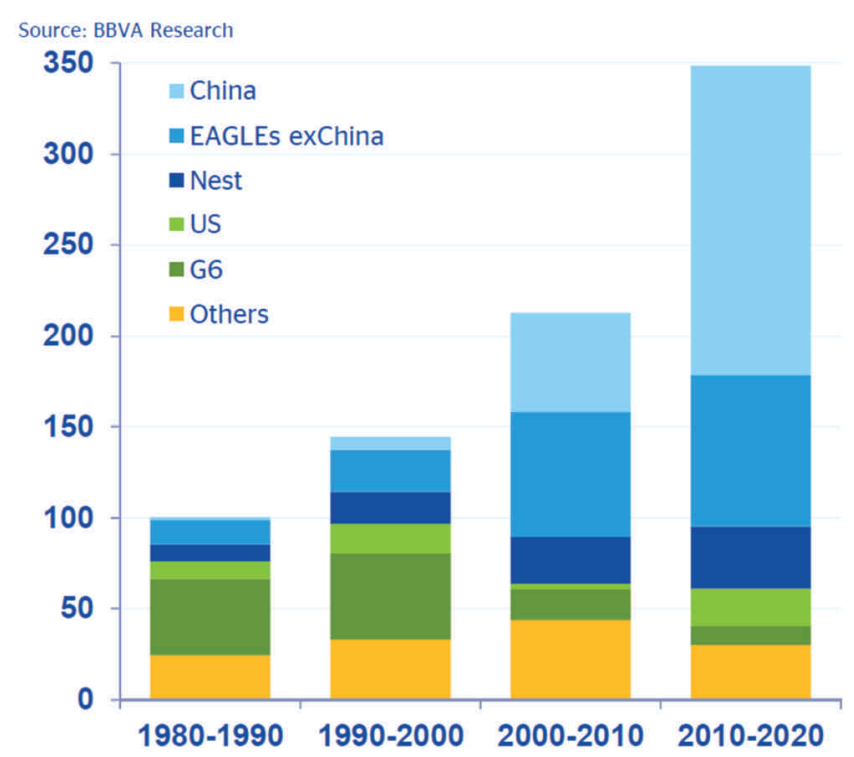

Fig. 1. Global amount of vehicles (in million pieces) [1]

One way to reduce the emissions is to minimize the fuel consumption. There are several methods to achieve it according to the combustion engine, i.a.:

1. through controlling the drivetrain working properties in a way, which makes it possible for the engine to work in its maximum effectivity field,
2. through reducing the fuel volume dosed to the engines combustion chambers; it may cause a reduction of the vehicles traction properties and increase in emissions.

Within this research, a series of virtual rides with a passenger vehicle in driving cycles were performed. To achieve the simulation the Road Load Engine Simulator was used. The Simulator is one of the research stands of the Chair of Road and Agricultural Vehicles in the Opole University of Technology. Binary readings of the engine characteristics and velocity profiles of the driving cycles are downloaded to the Simulator to enable the test to run without the actual vehicle model or its drivetrain.

The rides were performed in five variants of engine throttle inclination regulator settings, in real and synthetic driving cycles. The chosen velocity profiles were measured in real suburban driving conditions near the Opole city. During those on-the-road measurements the driver was controlling the vehicles load with an intention of achieving maximum driving dynamics (cycle 1) and the lowest possible fuel consumption (cycle 2). For comparison purposes a synthetic cycle NEDC (New European Driving Cycle) was used. Figure 2 depicts the examples of driving cycles velocity profiles, which were used in the simulation.

\section{The influence of the regulator settings on the throttle repeal speed}

The vehicles momentary velocity depends on one hand on the will of the driver, and on the other hand on the conditions deriving from the environment (i. a.: the road topography, atmospheric conditions, and other driver maneuvers). The driver using the acceleration pedal choses the proper engine torque amount, which is delivered to the wheels in accelerating, engine braking or constant velocity driving processes.

Modern drivetrains based on a combustion engine are often equipped with the ETC (Electronic Throttle Control) system. In ETC the acceleration pedal is connected with the throttle by electrical wires. The input signal derived from the pedal is converted by the engine control unit according to an algorithm and sent to the throttle electronical actuator. While the system is working, the throttle plate and accelera- 
tion pedal inclinations are checked frequently. It allows an almost immediate diagnosis of any eventual malfunction of the system parts.

a)

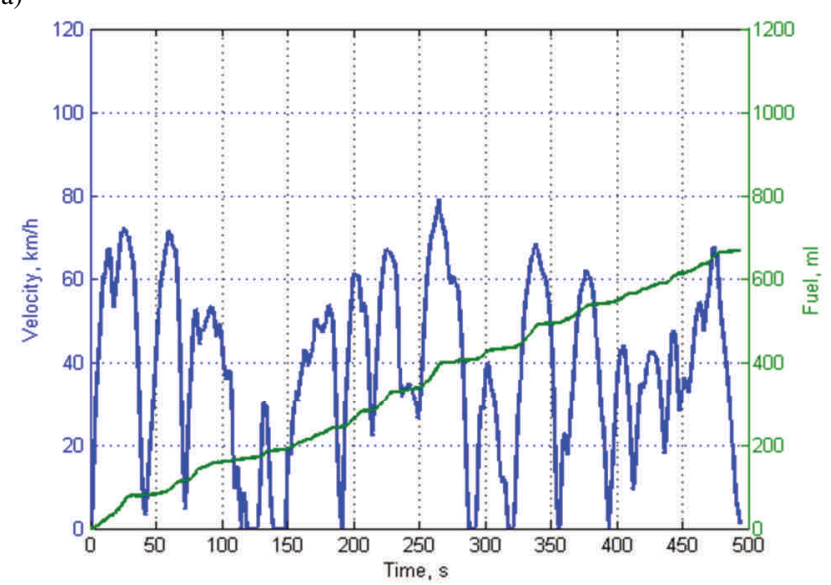

b)

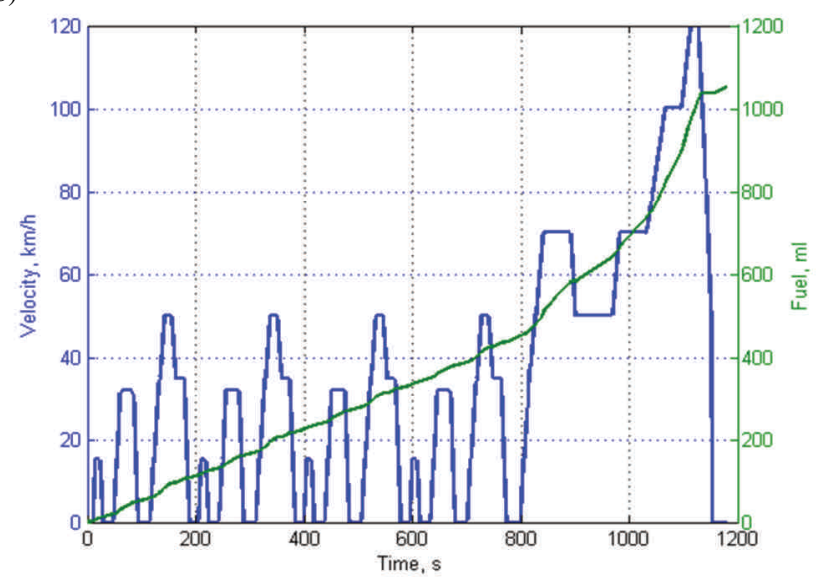

Fig. 2. Exemplary driving cycles, which were used in the simulations: a) driving cycles measured in real suburban driving conditions, b) NEDC

The Simulators software allows changing the settings of the throttle inclination regulator. Modifications of the settings influence the rapidity of the throttle reaction on the inducing acceleration pedal signal. Figure 3 depicts the noted momentary repeal speeds of the throttle plate. The results derived from the rides in $\mathrm{V} 1, \mathrm{~V} 2, \mathrm{~V} 4, \mathrm{~V} 5$ regulator settings variants were compiled with the base V3 setting result. According to figure 3 the throttle repeal speed increases subsequently in the order of the variants numbers (starting with V1, ending with V5). The dense clouds of points, characterizing the mostly noticed repeal speeds, occupy even wider surfaces, which demonstrate that the inclinations of the throttle plate were changing more and more dynamic.

The influence of the velocity profile on the throttle working parameters is also noticeable. Simulation of a dynamic suburban cycle was marked with higher throttle plate repeal dynamics, than the economic cycle simulation. This fact confirms the achievement of aims in the real driving measurements. In this case the higher throttle repeal speed is an evidence of higher repeal speed of the acceleration pedal and more sudden use of the vehicles acceleration potential.
The clouds shape should also be considered. In the real driving cycles the highest point dense can be noticed in the center of the plot and becomes the shape of a straight line (V1). In the next plots it becomes more and more the shape of a rhombus (V5). In the synthetic cycle the shape of the $\mathrm{V} 1$ cloud reminds a straight line and in the next plots becomes more and more a rectangle in the V5 variant. The highest point concentration occurs in the summits and in the middle of the sidewalls of the rectangle. Such velocity distribution of the throttle plate indicates the cyclicality of the movement phases, which is typical for the synthetic NEDC driving cycle. In contrast to the real driving cycles, in the NEDC the processes of acceleration and velocity decreasing are led with the same intensity in all cycle modules and the constant driving velocities are held at the same level (in the city traffic part of the cycle).

\section{The influence of regulator settings on the positioning of the mostly used area of the engine characteristic}

According to the changing conditions of the vehicles engine, its useful efficiency is changing in a high range of values. It is determined not only by the properties of the engine, but also by its working parameters, which are forced by the movement of the power receiver, as is the vehicle.

The changes of the throttle plate inclination have an effect in the intake manifold air pressure. As a result, there occur changes of the volume of air and fuel mixture provided to the cylinder, influencing the torque value, which the engine generates in given conditions. It follows that the settings of the throttle inclination regulator affect the momentary power supply while driving with often changes in the inclination of the power supply control component, thus in the so-called undefined states.

Diversification of possible undefined states inducements is an important issue in the development of a universal method for building the engine characteristics as appropriate to the specific transition phases of a vehicle. Unstable conditions of the engine operation occur mainly in the powering phase, while changing the travel velocity.

Figure 4 depicts the isoclines of the velocity characteristic of torque, used by the virtual engine. Additionally the in-cycle mostly noticed points of the characteristic were marked. The changes in throttle inclination regulator settings didn't cause radical differences in the points positions on the graphs plotted for the same driving cycle. The percentage magnitudes, which describe the use summits were changing, what is shown in the a) part of the Fig.e 5 .

The velocity profile course of the driving cycle determines the engine load during the test. As shown in Fig. 4, during the simulation of dynamic driving, the engine worked mostly in conditions of high or low load and low and medium engine speeds. In the simulation of economical driving, the engine load is lower at similar engine rotation speeds. In NEDC simulations, the engine load is focused around about $30 \mathrm{Nm}$ and the rotation speeds are between 2000 and 2500 rotations per minute. 
a1)

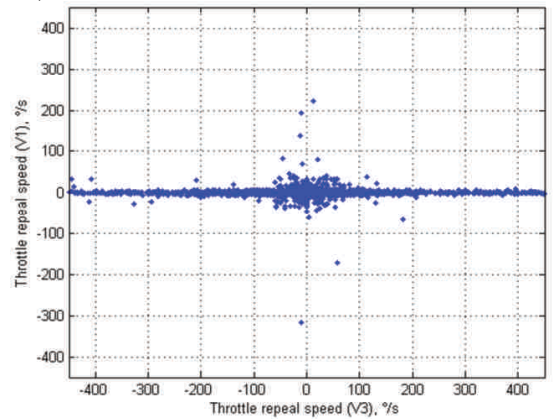

b1)

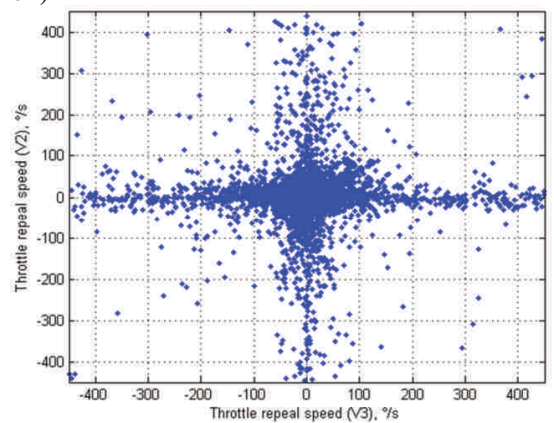

c1)

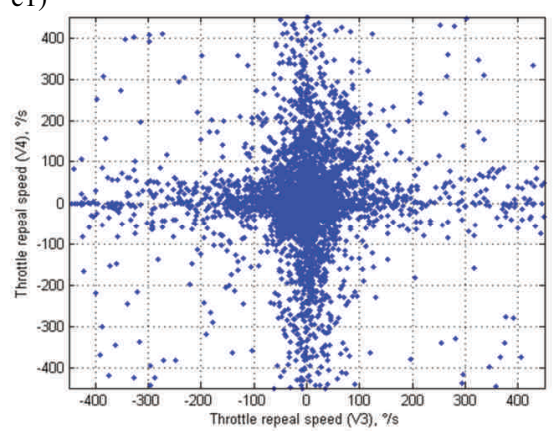

d1)

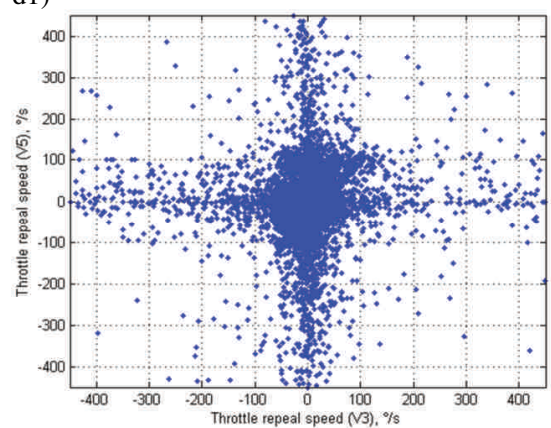

a2)

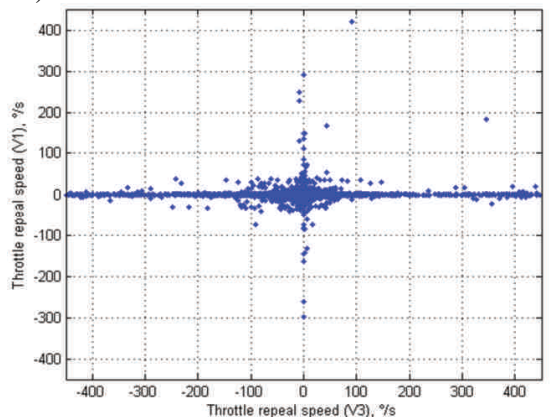

b2)

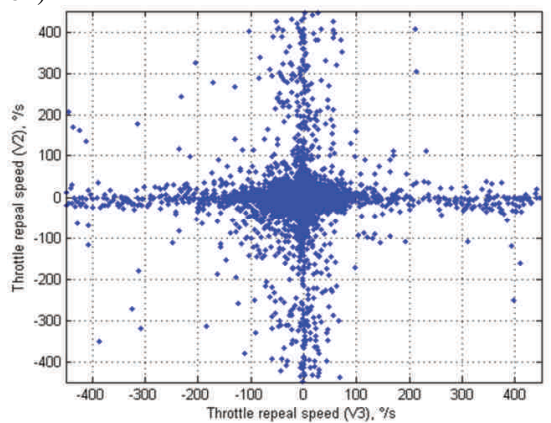

c2)

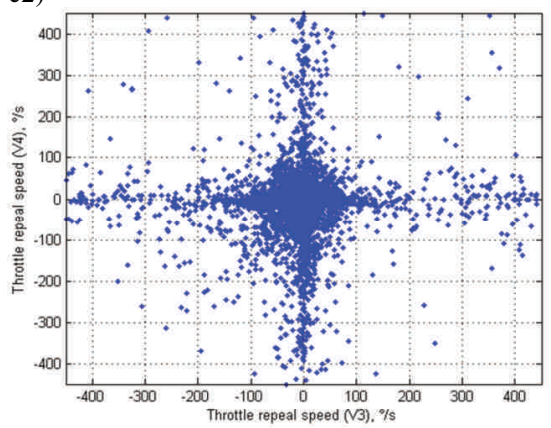

d2)

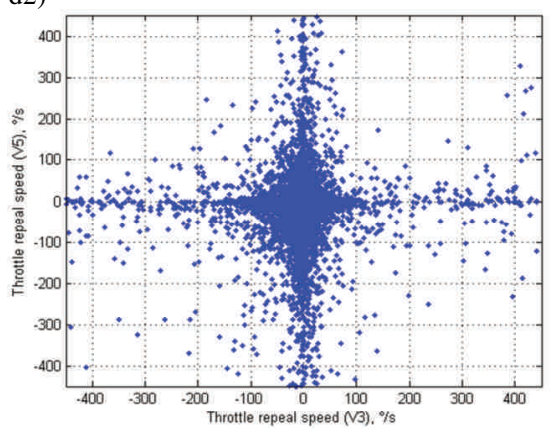

a3)

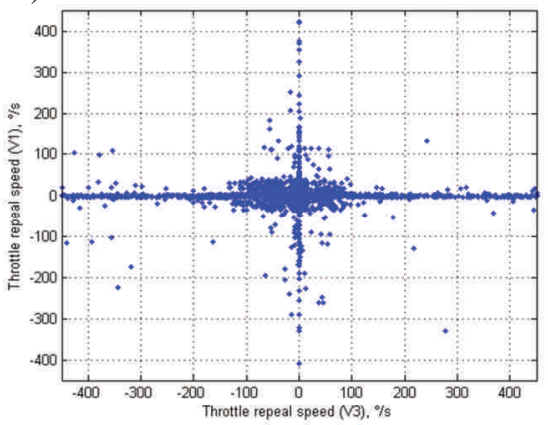

b3)

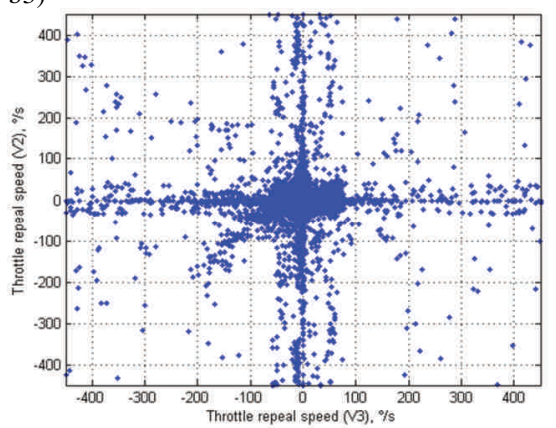

c3)

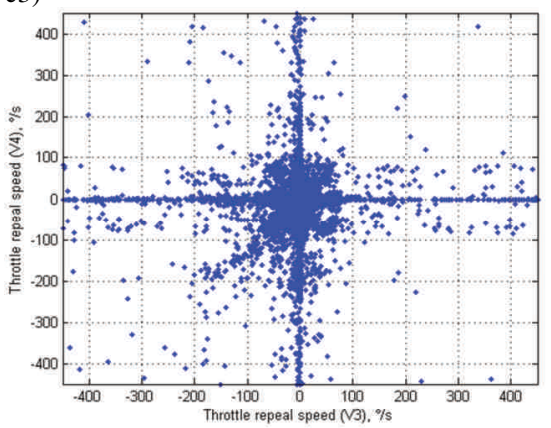

d3)

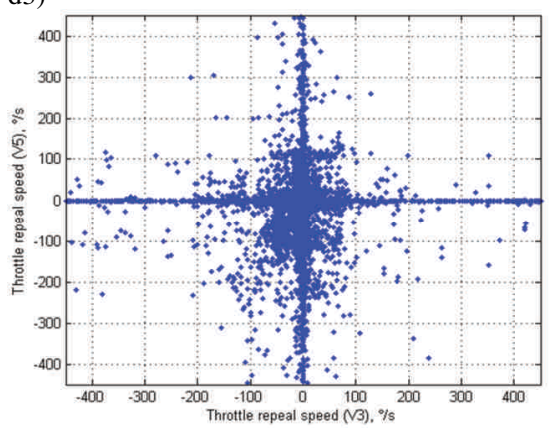

Fig. 3. Comparison of angular velocity of throttle movement for the individual variants of controller settings with the base variant (V3): a) $-\mathrm{V} 1, \mathrm{~b})-\mathrm{V} 2, \mathrm{c})-\mathrm{V} 4, \mathrm{~d})-\mathrm{V} 5 ; 1$ - cycle 1,2 - cycle $2,3-$ NEDC cycle

It can be derived from Figure 4, that the most commonly used range of engine rotation speeds starts with the idling velocity and ends within $2500 \mathrm{rpm}$. According to the most commonly used low load $(5.5-16.5 \mathrm{Nm})$ it should be noted, that this area of engine's load characteristic is highly unfavorable, because of its low overall efficiency.

The results of such tests, along with the use of the velocity characteristics of the useful efficiency, may allow the selection of such throttle plate working parameters which will allow the engine to work as close the point of its maximum efficiency as possible. A considerable part of the mileage fuel consumption and exhaust gasses emissions is generated during the acceleration processes. At the same time the torque development depends on the throttle inclination changes. It may be wise to select the optimal throttle inclination regulator settings algorithm for all these parameters. 
a1)

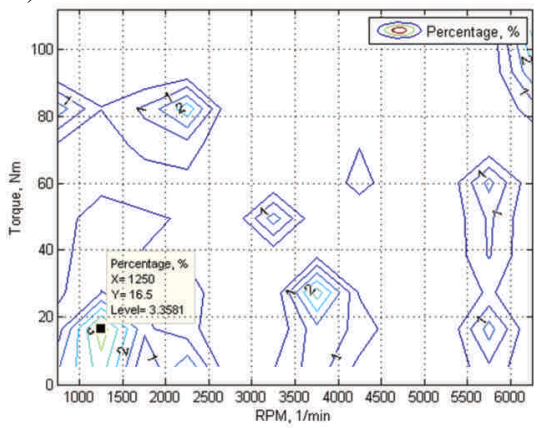

b1)

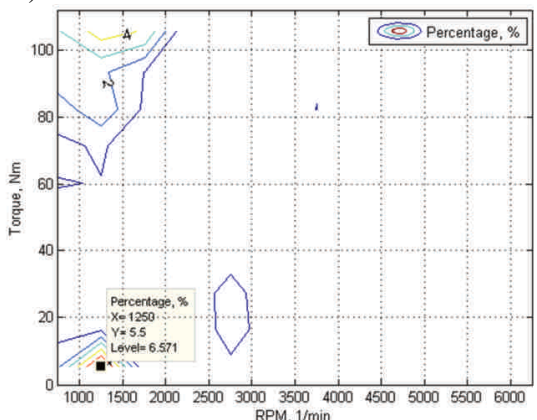

c1)

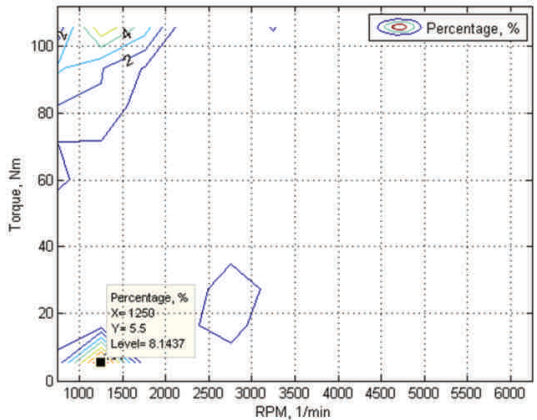

d1)

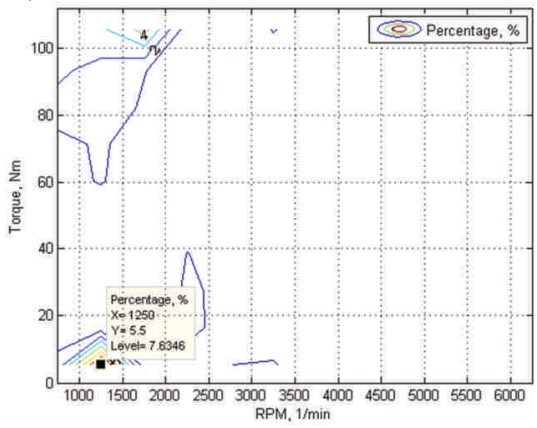

e1)

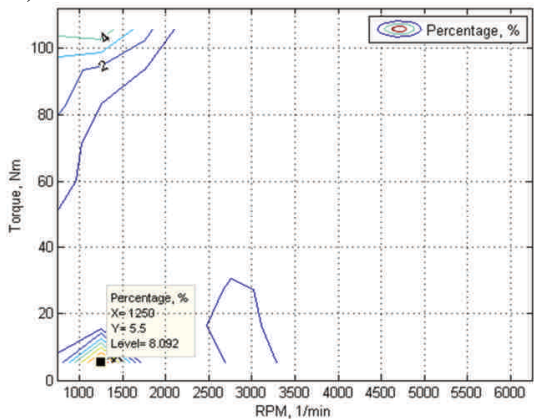

a2)

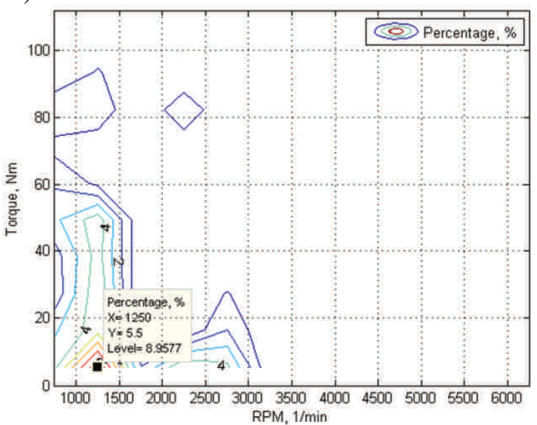

b2)

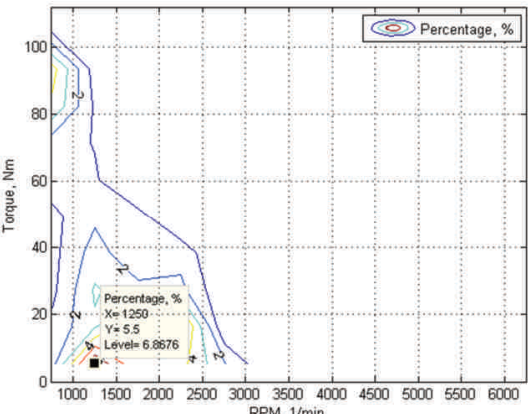

c2)

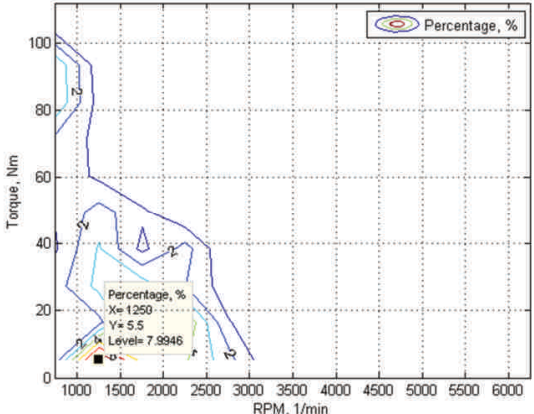

d2)

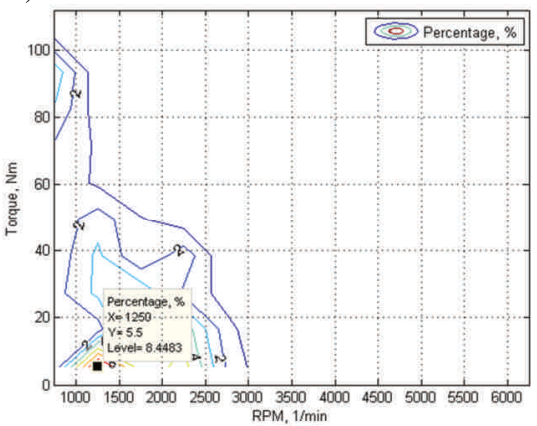

e2)

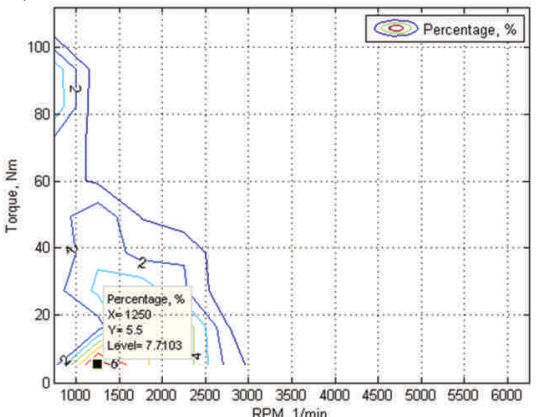

a3)

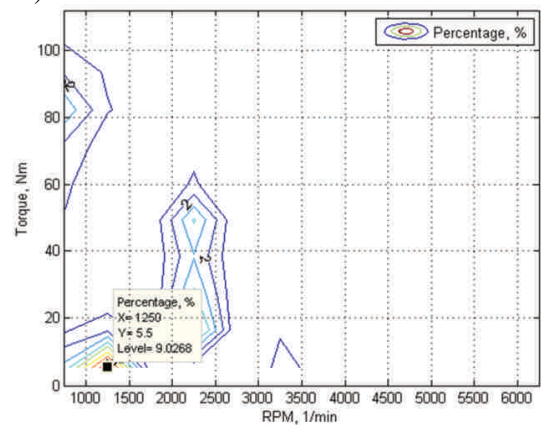

b3)

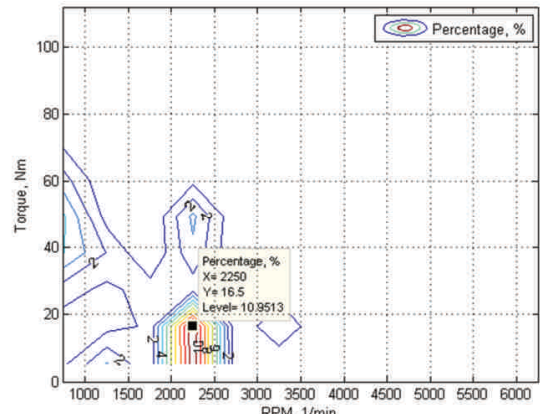

c3)

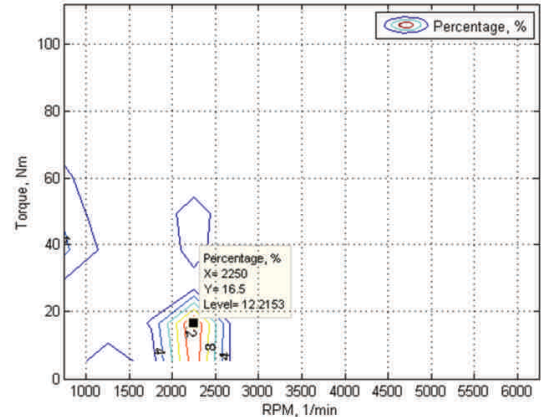

d3)

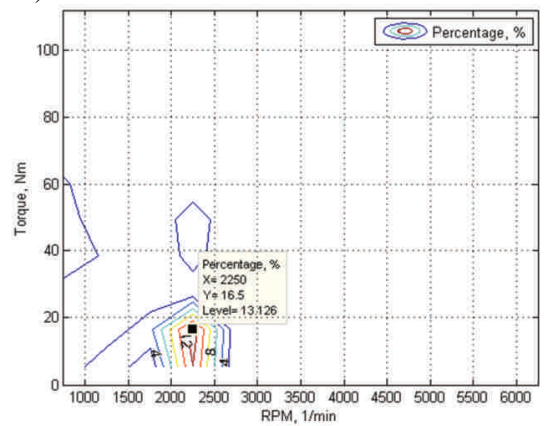

e3)

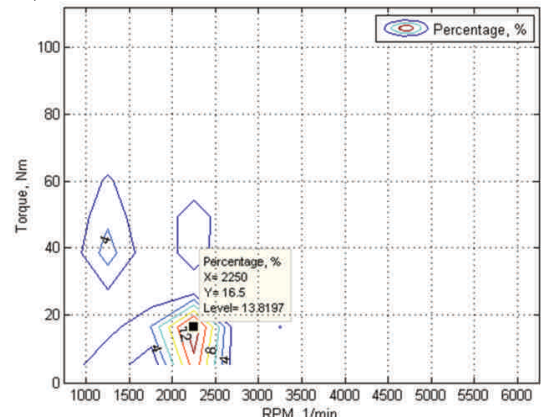

Fig. 4. Most commonly used points of the speed characteristic of engine torque: a) - V1, b) - V2, c) - V3, d) - V4, e) - V5; 1 - cycle 1,2 - cycle $2,3-$ NEDC 
4. Effect of regulator setup on fuel consumption in driving cycles

The basic energetic trait of a vehicle engine is its fuel consumption. It is dependent on engine and drivetrain efficiency and motion energy consumption, which describes the amount of energy at the drive wheels needed to traverse given length of the road. Factors which most significantly affect fuel consumption are the frequency and intensity of acceleration phases, which decide the mean value of acceleration, and the engine idling time. There are potential possibilities to reduce fuel consumption in city driving by minimizing the energy dissipated during braking and shortening the engine idling time.

a1)

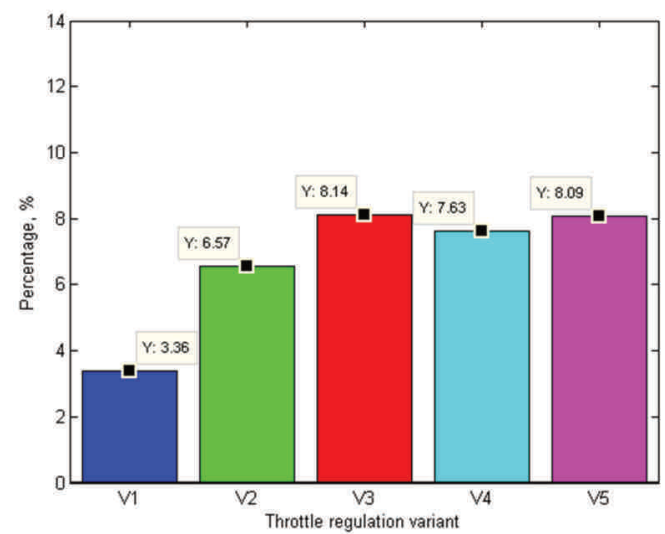

a2)

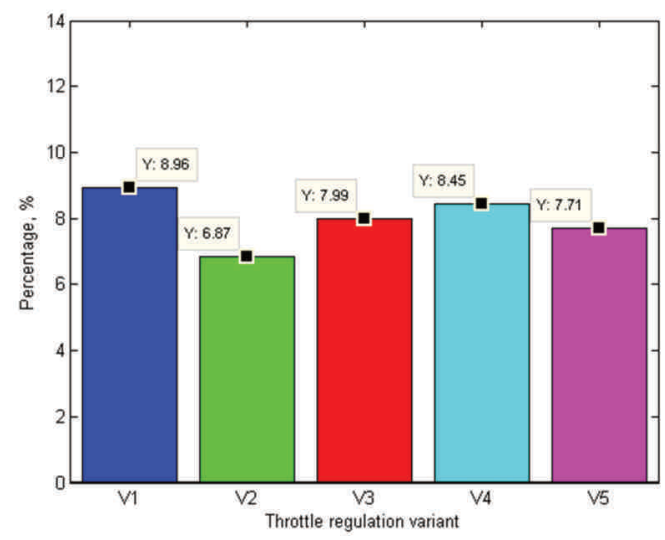

a3)

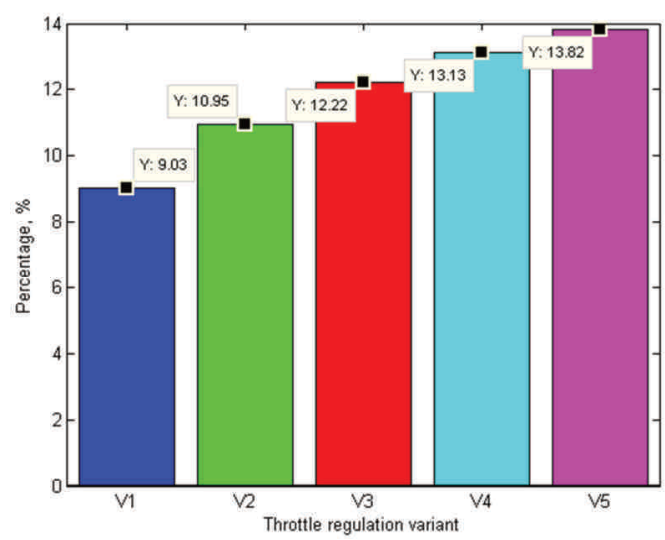

Partial characteristic of engine power, torque and specific fuel consumption in the function of engine speed are applicable for the analysis of vehicle motion characteristics and its energy consumption. They are prepared for selected power supply mechanism positions (mostly given as percentage values). Such curve courses usually show some characteristic traits. Maximum spark ignition engine power is usually situated at lower than top engine speed. Maximum torque engine speed is always lower than maximum engine power speed. On the other hand, minimum specific fuel consumption is situated at the engine speed higher than maximum torque speed and lower than maximum power speed.

b1)

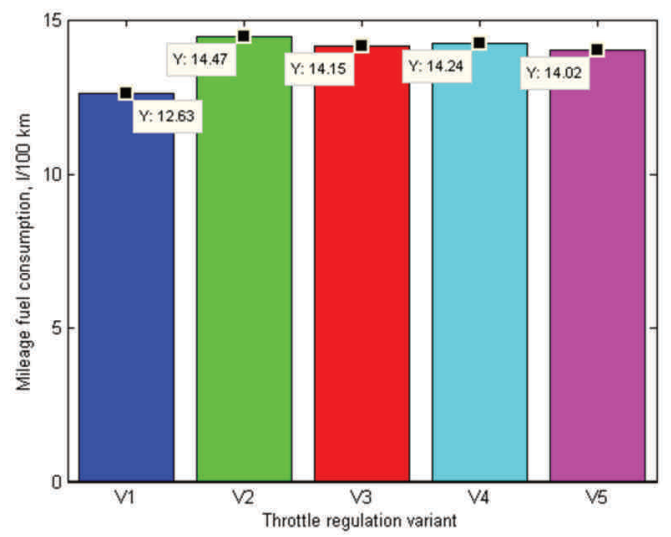

b2)

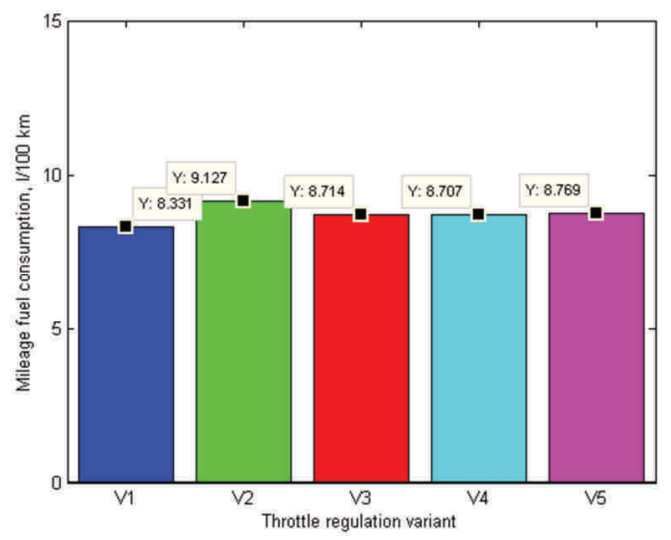

b3)

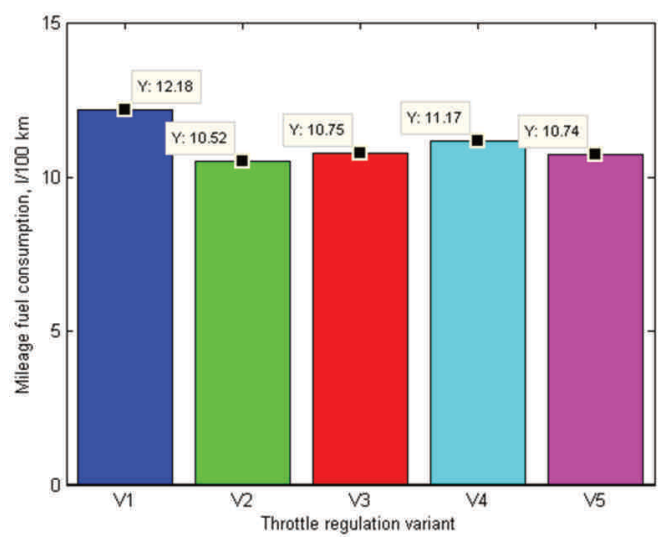

Fig. 5. Summaries of: a) - percentage values of mostly used points of the engine torque characteristic, b) - mileage fuel consumption; 1 - cycle 1,2 - cycle 2, 3 - NEDC 

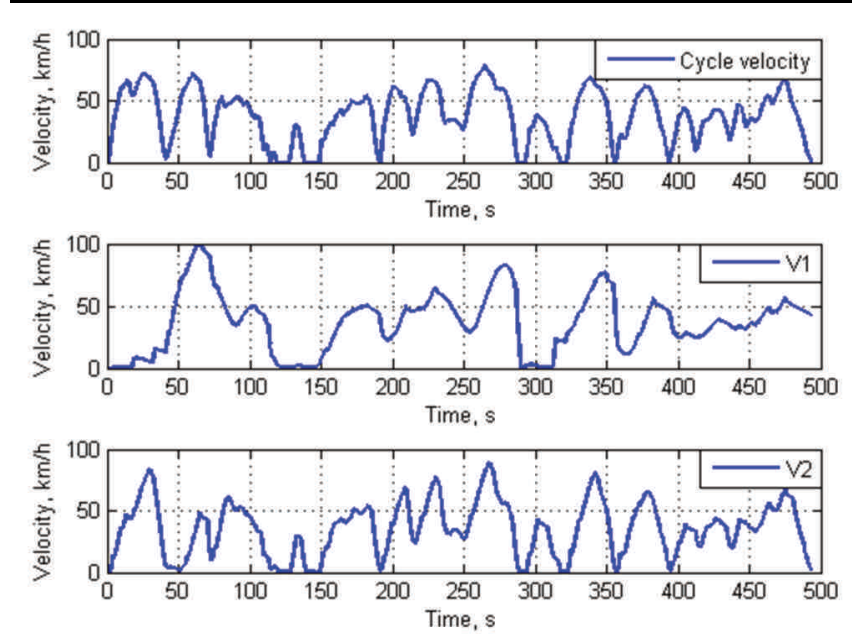

Fig. 6. Velocity courses versus time curves: on the top - the velocity profile of the Opole city dynamic cycle, in the middle - the velocity profile carried out for the V1 setup, at the bottom - the velocity profile carried out for the V2 setup

Comparisons of mileage fuel consumption in Fig, 5 b) show values of virtual fuel consumption obtained in drive cycles in relation to a length of 100 kilometers. The lowest fuel consumption in real drive cycles was achieved for V1 throttle regulation setting, while in synthetic cycles the V1 setting showed the highest fuel consumption. In the same synthetic cycle, the lowest value of fuel consumption was measured for V2 variant, which yielded the highest fuel consumption for real drive cycles. The remaining versions of regulator settings generated comparable results for both cycle types. It is worth noting that for V1 variant the throttle was repealed at very low speeds, which significantly impaired acceleration capabilities. The reason for this is a poor adherence of realized velocity profile in comparison to the assumed one, as is shown in Fig. 6. The V2 variant showed a much better adherence of velocity profiles. The effect of driving cycle velocity profile on mileage fuel consumption is also noticeable. Dynamic driving was characterized by $50 \%$ larger fuel consumption than economical driving.

\section{Bibliography}

[1] BBVA Research: The Future of World Car Fleet: The Road Ahead, 2012.

[2] SIŁKA, W. Teoria ruchu samochodu. Skrypt 192. Dziat Wydawnictw Politechniki Opolskiej, Opole 1996.

[3] MAMALA, J. Kompensacja niedostatku siły napędowej w procesie rozpędzania samochodu osobowego. Zeszyt 290, Oficyna Wydawnicza Politechniki Opolskiej. Opole 2011.

Krystian Hennek, MEng. - Faculty of Mechanical Engineering at Opole University of Technology. e-mail: K.Hennek@po.opole.pl

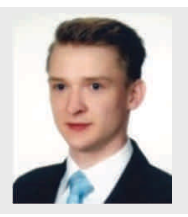

Jarosław Mamala, DSc., DEng. - Faculty of Mechanical Engineering at Opole University of Technology.

e-mail: J.Mamala@po.opole.pl

\section{Summary}

By analyzing the obtained research results it can be seen, how significant is the effect of throttle inclination management method on vehicle dynamics, fuel consumption and driving safety. Slow regulation of throttle plate inclination helps to reduce fuel consumption; however it impairs dynamic properties of the drivetrain. On the other hand, quick regulation of throttle plate inclination causes a significant clipping of the induced repeal angle - in response to this, the ECU starts increasing the fuel dosage, which in turn causes the mileage fuel consumption to increase significantly. However, as can be noted from the conducted research, it is difficult to clearly point out which of the proposed throttle inclination regulator settings would allow to minimize fuel consumption while maintaining adequate vehicle drive dynamics. The analysis of simulated drive cycles allows to assume that conventional regulators only partially fulfill the requirements of minimizing fuel consumption while retaining adequate vehicle drive dynamics. Therefore, while using this class of throttle regulators it is required to achieve a certain compromise between low fuel consumption and good drivetrain dynamics. Velocity profile and road conditions have a substantial effect on fuel consumption; however driver behavior is the most important factor affecting it. The driver-dependent style of application of throttle inclination change is the factor that has the biggest effect on fuel consumption. In this case, an adaptive regulator has to be used in the throttle plate management system to correct its settings depending on driver behavior. This solution would allow to keep fuel consumption as low as possible, while retaining satisfying vehicle drive dynamics. Only this control strategy would allow to control throttle inclination for all road conditions and driver behaviors in a way that would minimize fuel consumption and retain drive dynamics that could be deemed satisfying for each driver. The use of adaptive regulators in throttle inclination control systems will be the further scope of the authors' research.

[4] MAMALA, J., BROL, S., GRABA, M. Engine control unit testing by hardware-in-the-loop simulation, Solid State Phenomena. 2014, 214, 67-74.

[5] BIENIEK, A., GRABA, M., LECHOWICZ, A. Sterowanie układem wtryskowym silnika ciągnika rolniczego w aspekcie poprawy jego własności ekologicznych. Combustion Engines. 2011, 146(3), 1-8.

Mariusz Graba, DEng. - Faculty of Mechanical Engineering at Opole University of Technology. e-mail:M.Graba@po.opole.pl 